Portland State University

PDXScholar

Dissertations and Theses

Dissertations and Theses

1978

\title{
Alternative Living Situation for Indian Youth
}

Colleen Lynn Langer Yost

Portland State University

Lloyd Blackstone Pinkham

Portland State University

Follow this and additional works at: https://pdxscholar.library.pdx.edu/open_access_etds

Part of the Criminology and Criminal Justice Commons, Indigenous Studies Commons, and the Social Work Commons

Let us know how access to this document benefits you.

\section{Recommended Citation}

Yost, Colleen Lynn Langer and Pinkham, Lloyd Blackstone, "Alternative Living Situation for Indian Youth" (1978). Dissertations and Theses. Paper 2819.

https://doi.org/10.15760/etd.2814

This Thesis is brought to you for free and open access. It has been accepted for inclusion in Dissertations and Theses by an authorized administrator of PDXScholar. Please contact us if we can make this document more accessible: pdxscholar@pdx.edu. 


\title{
ALTERNATIVE LIVING SITUATION \\ FOR INDIAN YOUTH
}

\author{
by \\ COLLEEN LYNN LANGER YOST \\ and \\ MONSIEUR LLOYD BLACKSTONE PINKHAM
}

\section{A PRACTICUM SUBMITTED IN PARTIAL FULFILLMENT OF THE REQUIREMENTS FOR THE DEGREE OF}

\author{
MASTER OF \\ SOCIAL WORK
}

Portland State University

1978 
APPROVED:
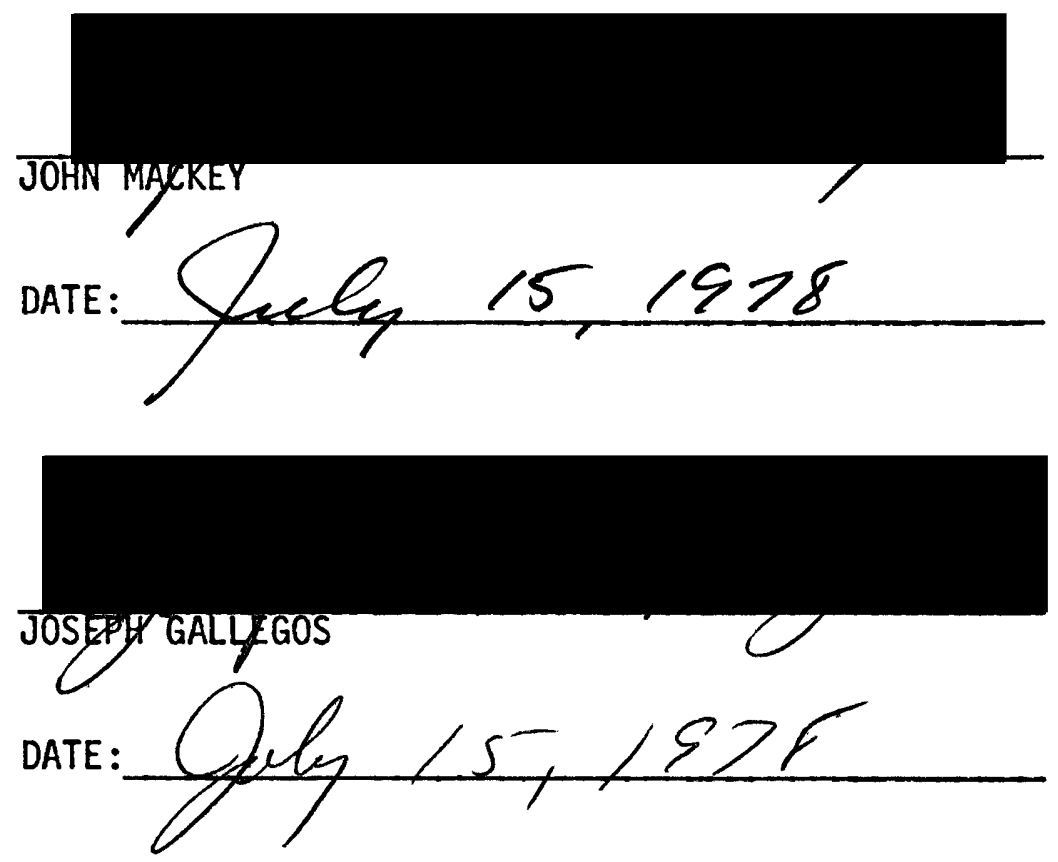
TABLE OF CONTENTS

PAGE

ACKNOWLEDGMENTS

CHAPTER

I INTRODUCTION $\ldots \ldots \ldots \ldots \ldots \ldots \ldots \ldots \ldots \ldots \ldots \ldots \ldots$

Hypothetical Case History ............. 5

Theoretical Framework ............... 17

Hol istic

Alienation

Socialization

II HISTORICAL BACKGROUND $\ldots \ldots \ldots \ldots \ldots \ldots \ldots \ldots \ldots, 21$

Problem Statement ................. 22

Project Proposal $\ldots \ldots \ldots \ldots \ldots \ldots \ldots \ldots . . \ldots 24$

II A MODEL FOR CHANGE $\ldots \ldots \ldots \ldots \ldots \ldots \ldots \ldots \ldots \ldots . . \ldots \ldots$

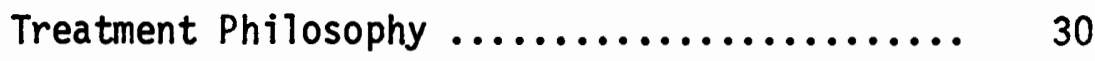

Project Intent $\ldots \ldots \ldots \ldots \ldots \ldots \ldots \ldots \ldots \ldots . . \ldots \ldots$

Goals/Objectives/Tasks:

An Introduction ................... 34

National Standards and Goals ............. 37

IV PROJECT IMPLEMENTATION $\ldots \ldots \ldots \ldots \ldots \ldots \ldots \ldots \ldots . \ldots \ldots$

Operational Methods ................. 44

Relationship to Tribal Juvenile

Courts .......................... 45 
Program Financing

Description of Clientel $\ldots \ldots \ldots \ldots \ldots \ldots .47$

Description of Services ............... 48

Staffing Nature and Patterns ........... 49

Cottage Structure ................. 52

Evaluation and Monitoring Procedure ........ 53

Method $. . \ldots \ldots \ldots \ldots \ldots \ldots \ldots \ldots \ldots . \ldots \ldots$

Subjects

Procedure

Effort

Efficiency

Impact 


\section{ACKNOWLEDGMENTS}

We wish to express gratitude to

Frank Peterson, M. T. and Joseph Gallgos

for their assistance in preparing

the practicum. 


\section{CHAPTER I}

\section{INTRODUCTION}

The very definition of majority implies superiority, and it is often the prevailing assumption of those in a majority group that their beliefs are in fact superior. It is often the natural inclination of those who hold this assumption to either stamp out any other competing bel iefs or to forcibly persuade others to hold their own beliefs.

With this in mind it is necessary to examine the beliefs and values of the 'majority group', the non-Indians, as well as the minority, traditional Indian groups beliefs to see where the two differ and the consequences of such forcible persuasion upon the minority group. The following is an outline of some cultural differences between the majority non-Indian group and the traditional Indian minority.

Majority, minority groups are being generally defined with no regard for the individuals who make up the groups for the purpose of establishing and emphasizing the broad cultural differences and the subsequent conflicts which arise. It is granted that these groups are not mutualiy exclusive and that there are common beliefs, but for the purpose of examining where conflicts between the groups arise, no mention of the non-conflicting common ground areas was made.

In light of these differences, the traditional Indian is in conflict with the majority group who 'rules' his world. Only through reinforcement of the traditional Indian's beliefs within the context 
of the non-Indian's can the two relate in close coordination with minimal conflict.

Specifically, these conflicts will be examined for a small group of traditional Indians who are highly susceptible to forcible persuasion and are easily damaged by the social discrepancies: Indian youth.

Indian youth, who are in the process of formulating their own lifetime value sets, require discernable models from which to choose their own patterns.

To those youth who have been declared adjudicated del inquents, the ruling law, or non-Indian law, has the right to say "you must leave your home and live where we put you". These are the youth who are removed from their homes in an attempt to 'make them fit' into non-Indian society, thus destroying their traditional beliefs. These youth would benefit much more from a traditionally strengthening alternative which would enable them to cope effectively with society through confident assertiveness and clear direction. 


\section{CULTURAL CONFLICTS - "THE INDIAN WAY"}

INDIAN

As a nation, tribe, or individual, each seeks harmony with Mother Nature, including people, in order to get along, resulting in peace and happiness.

Judge other people and ourselves by what they are and how they act as individuals; not what they have.

We must work in accordance with Mother Nature's time schedule; During spring, Summer and Fall we must prepare for Winter. With each season we must show an appreciation with a feast of thanks to the creator for another cycle of life.

During the feast of the first salmon, celery, root or huckleberry, it is a time for the enjoyment of other people and the blessing for the great foods. But it serves as an appreciation to the creator and a sign to all tribal members that thanks has been given and the harvest of each respective food may begin by all.

Judge each person separately, look at reasons for his actions first, then his/her understanding of the norms of tribal society.

During a tribal feast, it is a time of sharing gifts with other tribes and tribal members to express their reverance for Mother Earth by showing their generosity in appreciation to the creator for another cycle of life.

Each man must seek a vision, then and only then will he understand his own individual ism.
NON-INDIAN

Make things for financial gains and money, resulting in power and material possessions.

In America, we must keep up with the Jones in material achievement and monitary success.

As the slave of ambition, we must work hard all the time.

Doing something that leads to a pleasant memory of something done, not of the people or a deeply related community religious act.

Judge a man by what he ought to be (idealism).

Regard nature as only something to be used and have lost reverence for nature.

External conformity tends to remove one's own individualism. 
INDIAN

Freedom of individual choice and respect of another's vision.

Equality, the measure of a person's spirituality, what he is inside, (wise, generous, good).

Education, to learn the wise unwritten oral teachings of our elders. You must know, before you can teach. Our elders also care for the young.

Religion, the land is our alter, the sky our church, the sun from the east tells of his almighty presence in watching over us with each new day, the Eagle carries our message to him. We know that he controls the cycle of life and the patterns of renewal for the Mother Earth, air, fire and water. Most importantly of all, he gave us a gift of a child, pure and free of sin to replenish our own.
NON-INDIAN

Freedom of individual choice is measured in terms of your position on the social ladder; the higher you are on the social ladder, the more freedom you have to make decisions.

Equal ity of opportunity.

Treat elders with little respect, and reward them by putting them in a senior citizen's home, where they will never know the warmth of their grandchildren.

In the beginning a man came to our village with a plow and bible in hand; now he owns the land, teaching us of the bible and talking of a child that is born with original sin. 
Hypothetical Case History

The following is a hypothetical case which explifies what, in many cases, happen to Indian Youth.

Terry Dakota is a 36 year old Indian who was born on a reservation. Terry was taken from his natural parents and has been raised in numerous foster homes. Terry is separated from his wife and two children, and does not know their whereabouts. He is a high school dropout. He has no trade. Terry is overweight and an alcoholic. He has drifted from town to town and has finally settled in a city in the Northwest. He has been to numerous social service agencies with no success in finding the help he requires to deal with his problems. Terry was arrested for being drunk in public and has been forced by the court to go to an alcoholic rehabilitation clinic.

Terry Dakota and many other Indian children have one strike against them the moment they are born; they are born Indian in a predominantly white society. The character of the American Indian is generally drawn in a derogatory manner. Indians have been seen as an invisible counterpart of the dominant American society since the time European explorers first set foot on the American continent. White society has placed a stigma on Terry and others like him. It is ironic that in their effort to secure funds to operate tribal service programs, Indian people must portray themselves to funding agencies in a manner which reinforces that stigma. Goldie Denny, Social Service Director for the Quinault Nation, has expressed it this way; "We have to prove that we are drunker, abuse our children more, and are generally worse 
than anyone else to get money to operate our program." $\bar{\imath}$ H.C. Townley has stated that historically, the federal/Indian relationship has been a parent/child relationship. ${ }^{2}$ Thus, white society has been placed in a super-ordinate, or superior position, with the Indians being a subordinate group.

Children, in traditional Indian culture, are looked upon as a gift. In a modern day reality an Indian child born on a reservation is at a disadvantage from the moment of his birth. His initial socialization which is provided by the extended-family system induces not only that which is good from traditional Indian culture but gradually incorporates an awareness of a life-long dependent state, dependency on federal and state governmental services (e.g., B.I.A. Social Services, Washington State D.S.H.S., Family Services, Oregon C.S.D.). This dependent relationship creates an adult/child whose emotional and social maturation processes are arrested. The efforts of these agencies are all too often directed toward the agency's own best interests, rather than that of the $c$ lient. This relationship destroys thought and initiative, or worse, provides no reason for their development. Lacking opportunity for self-determination to make decisions which count, the Indian develops a life-long negative expectation of himself. Terry may have experienced a partial impact of dependency on the federal and state governmental services, the same as his extended-parent family system who were influenced by the social institutions of the non-Indian

IStatement by Goldie Denny, Social Service Director, in a personal interview, Tahola, Washington, July, 1976.

${ }^{2}$ Townsley, H.C., One View of the Etiology of Depression in the American Indian, p. 8. 
dominant culture.

Terry's dependency on the federal and state government services was in the form of foster care. The quest for "the best interest of the child" has been the professed principle which governs the practice of foster care for Indian children. There is a wide variation in the way an individual state's agents or courts puts it into practice. ${ }^{3}$ Society's agents fall back on their own personal values and moral systems in evaluating the child rearing of any particular family who comes before them. The agent, being the judge, social worker, or probation officer, makes some determination of the child's needs and the family's ability to meet those needs. This estimation may be based on his own class values which can differ radically from the culture of the child and the values of the child's family.

For a long time the state and federal government agents have regularly intruded into the Native American families, especially those living on reservations. However, these problems are not restricted to the reservation, they also affect Native people living in urban areas. The intrusions are (1) where a child is held to be dependent-abandoned; (2) where a child is considered to be neglected; (3) when a child is considered delinquent; and (4) to meet a "deprived" child's educational needs.

On most reservations, the U.S. Bureau of Indian Affairs has made it a policy to send Indian children as young as six years old to faroff boarding schools. This practice has formeriy been wide-spread, with the overt aim of "helping" Indian children enter more easily into

3rodham, H., Children Under the Law, Harvard Educational Review 43: No. 4 (Nov. 1973), p. 487-574. 
the mainstream of white American life. Now, B.I.A. says, the practice is confined to regions where other educational opportunities have not developed, where home situations are difficult or where deviant behavior exists. This educational practice has had a devastating effect on several generations of Indian children. ${ }^{4}$ It affects their family lives, their traditional native culture, their sense of identity and their ability as parents. This practice will undoubtedly have the same destructive impact on Indian children today. The message seems to be that it is better for Indian children to be raised by others than by their parents or their own people. 5

The Association on American Indian Affairs asserts that American Indian children today are regularly removed from their parent's homes by various government, volunteer, and religious groups for reasons of dependency-abandonment or neglect. They further assert that this practice often results in the separation of the children from their communities, reservations, and people. ${ }^{6,7}$ In the United States, one in every 200 Indian children lives outside of his home of origin. ${ }^{8}$ Approximately

(4). S. Senate, Special Subcommittee on Indian Education. Hearings. Washington, D.C.; U.S. Government Printing Office: 1969.

${ }^{5}$ Goldstein, G.S., The Model Dormitory. Psychiatric Annals, 4: No. 11 (November, 1974), 85-92.

${ }^{6}$ Association on American Indian Affairs, Indian Family Defense No. 1 (Winter, 1974).

7 W. Byler, S. Deloria, and A. Gurtwitt, Another Chapter in the Destruction of American Indian Families, Yale Reports, No. 654, (October 21, 1973).

8U.S. Senate, Special Subcommittee on Indian Education, Hearings, Washington, D.C.: U.S. Government Printing Office: 1969. 
$85 \%$ of all Indian children in foster homes are placed in non-Indian homes. 9

As Carl Mindell and Alan Gurwitt have stated, there are two trends which are both obvious and alarming: (1) American Indian children are being placed outside their natural homes at an enormous rate, and (2) they are given over to the care of non-Indians in very considerable numbers. 10

Indian children placed in off-reservation, non-Indian homes are at risk in their later development. When placed in these homes, the children are subject to ethnic confusion and a pervasive sense of abandonment with its attendant multiple ramifications. These problems combined with early childhood pre-placement experiences adversely affect their early adulthood and their potentials as parents. Families which have become disorganized or have had difficulties in providing for the needs of their children are usually well known to various agencies. A11 too often, neither tribal, state or federal agencies have made any real effort at early intervention and support for the child and his family. When things finally get bad enough, the only clear option appears to be placement.

Since Terry had been raised in numerous foster homes, it is likely that he led a confused and lonely childhood. At the time Terry was in

9 W. Byler, Statement before the Subcommittee on Indian Affairs of the U.S. Senate on April 8, 1974, Indian Child Welfare Program, Hearings before the Subcommittee on Indian Affairs, U.S. Senate, Washington, D.C.: U.S. Government Printing Office, 1975, (see pp. 1-11 of the present volume).

$10_{E}$. Mindell and A. Gurwitt, The Placement of American Indian Children--The Need for Change. The Destruction of American Indian Families, Association on American Indian Affairs, New York, 1977. 
foster care, it is highly probable that he was in a non-Indian home. In terms of Erikson, when working with people with personality disorders, you have to consider other things besides personal dysfunctions. 11 Not just individual dysfunctions but socio-cultural factors affected Terry's building of his self-image. Psycho-social factors also go into what makes a person a person. At the time when Terry was growing up, it wasn't popular to be an Indian. Being Indian carried a negative connotation. Because of the negative connotation, in building Terry's self-image he could have had problems. Possibly in foster care Terry received negative connotations as far as his identity is concerned. Dysfunction or deviance in the Indian sense derives from the disconnectedness that has become lonliness in the personal sense.

The oppression which exists does not allow most Indian children who have been placed in non-Indian foster care to live in the Indian way their natural families have learned to live. This creates serious problems for the person as he attempts to define himself in relationship to the Indian and non-Indian worlds. It requires that the person have confused definitions of self as a consequence of the oppression of the transitional processes. The lack of self-esteem and sense of self-worth, which is descriptive of many Indians, is directly related to the confusion and imbalance the Indian person experiences. 12 The Indian person is philosophically unable to separate himself from his world. The imbalance that he experiences reflects on the world and

11 E. Erikson, Childhood and Society, pp. 247-275.

12E. Blanchard, Mental Health: An Indian Point of View, Fall Lecture Series, 1976; School of Social Work, University of Washington, p. 11. 
is a reflection of the world on him.

Terry's educational experiences have no: been very successfui; he was a high school drop-out. Volumes have been written about the Indian experience with Western education. The conclusions reached by all these accounts are that this educational system conveys and supports the value system of the society it represents. The goals of the Western system required that the Indian person accept his status as a conquered person. It requires that he change his thought patterns to provide him with second-class status in a world where his labor and natural resources could be systematically exploited. 13

Byrde investigated a cross-over phenomenon in the educational performance of Indian students. ${ }^{14}$ These children achieve satisfactorily for awhile, then reverse themselves and show a steady decline in achievement. In examining past school achievement records taken from the fourth to sixth grades of 164 eighth graders, using the California Achievement Tests, their scores were found to exceed the national norms. However, at the seventh grade level the students 'crossed over' and their grades continually declined. Bryde hypothesized that psychocultural conflict during the period of adolescence causes personality problems which block educational achievement and that a comparison of the Indian students with white students would reveal significant differences which reflect such personal turmoil. All students were therefore given the Minnesota Multiphasic Personality Inventory and such

13E. Blanchard, Organization and Indian Women, Published paper, 1977, pp. 20-27.

14J.F. Bryde, The Indian Student: A Study of Scholastic Failure and Personality Conflict, Dakota Press, 1970. 
comparisons were made. The total Indian group revealed greater personality disruption and poorer adjustment. The more meaningfull, significant dimensions were feelings of rejection, depression, anxiety, and tendencies to withdraw, plus social, self, and emotional alienation. More important are the findings which compare Indian and white eighth graders. The Indian students were found to be poorer on twenty of the twenty-eight personality variables. They revealed themselves as feel ing more rejected, depressed, paranoid, withdrawn and al ienated from themselves and others. 15

This may be the reason behind why Terry never completed his formal education. With a lack of formal education to learn a trade and no trade, there is little chance that Terry could ever gain employment which would bring him beyond a low economic level. With this stigma Terry has to carry, no wonder he developed such a low sense of selfworth and esteem.

Terry's experiences in foster care and the experiences of not being raised by his natural extended famity affected his potential capacity as a husband and a parent. As stated earlier, the experiences children have with pre-placement and foster care adversely affect their own potential as parents. Terry's parents displayed their lack of responsibility to care for him. This display presented a negative role model as a parent for Terry. He fell into his parent's pattern of lack of caring for their children, due to undetermined reasons (most likely social environment). Children need to repeat their past. You

${ }^{15}$ Townsley, One View of the Etiology of Depression in the American Indian, pp. 8. 
tend to become the kind of parent your parents were. 16

Terry's physical conditions, being overweight and alcoholic, as viewed from a non-Indian assessment, indicate that he did not have a good family background, no good family relationship. Overweight and alcoholism indicate reflections of oral needs, needs for love and caring. With no positive love relationships, nothing inside of him gives him good support. You must have at least one good loving relationship around which to build others. The outside world is not supportive of Terry and the inside world lacks an early good parental relationship which would give him support. ${ }^{17}$ Alcoholism is a symptom of the need for caring. A lot of different things brought on different reactions. Mental stresses, personality disorders, psychic stimuli, all may have triggered his disorders; he turned blame inward.

For a more meaningfull assessment of Terry's problems and those of others like him, it would require an Indian person with a traditional frame of reference when dealing with Indian youth. Excess in drinking and/or eating leading to obesity and alcoholism are symptoms, in Terry's case, of deeper problems. Separated from his family at an early age, his tribal ties were weakened and Terry was left with no cultural support system. For the native American, the ramifications of such a culture are myriad. Tribal traditions and beliefs provide each member with a definable set of relationships, including a sense of belonging, a sense of order and most importantly, a sense of inner

16E. Erikson, Childhood and Society, (W.W. Norten Co., Inc., New York, 1963), pp. 247-275.

${ }^{17}$ C.S. Hall and G. Lindzey, Freud's Psychoanalytic Theory. Theories of Personality, pp. 45. 
strength. Emphasis on alcoholism may give the impression that this is the only mental health problem of Indians. Indeed, there is a tendency in the professional and popular literature on the subject to equate Indian mental health problems with alcoholism. Oftentimes, many symptoms of mental iliness, such as depression or anxiety, are marked by concurrent presence of alcoholism. The abuse of alcohol becomes identified as the illness, while the underlying mental or emotional problems are completely overlooked. 18

A state of unhappiness exists when things go wrong. We then experience a feeling of sadness or discontent. Being depressed is a gloomy mood which permeates a person's basic emotional disposition and largely determines how he perceives himself, his environment and perhaps most importantly, the future. Depression often takes the form of an unyielding conviction that all is totally hopeless. Reality is a resident of the past, future is fantasy. Depression leads to alcoholism for many Indians. Alcohol use may be seen as a self-prescribed medicant to combat feelings of depression and attenuate feelings of poor worth. 19

Terry chose alcohol as his means of combating his negative image of himself, having little or no positive feeling of self-esteem or worth, and also his failure as a husband and parent. Terry's relationship with his wife may have failed because he was seeking a relationship with her that he did not have with his natural mother, and/or

18 H.C. Townsley, One View of the Etiology of Depression In the American Indian, p. 5.

${ }^{19}$ Ibid. 
others significant women within the structure of the extended family: a loving and caring relationship. Possibly he could not find this in her, the result being separation.

Terry's drifting from town to town is indicative of his need to seek immediate help with his problems. The social service agencies he went to could not meet his immediate needs. He wants his needs met today, not tomorrow. His first encounter with a service del ivery system was possibly a negative experience. Some of the barriers he may have encountered are:

I. An Indian in an urban setting must rely on a service del ivery system of western medicine that was designed for and by the white majority-a fact that Blacks, Chicanos, and other minority groups have often pointed out.

II. Urban Indians often encounter what could be called bureaucratic run-around. Because the federal government provides no care for the individual Indian off the reservation, and local facilities take the attitude that Indian health care is a federal responsibility, the urban Indian may find that he has to fight to meet eligibility requirements.

III. A wide variety of attitudes impede Indian utilization of available programs. These are difficult to quantify, but are clearly a major barrier to Indians seeking help from mainstream health facilities. American Indians compla in about "not feeling welcome" and feel ing as though they were treated in a cursory fashion or even with outright hostility. They often say this is because "the people in the clinics don't understand our culture",

IV. Language, or at least semantic difficulty, may also prove to be an impediment. It has been noted that the florid English style of several tribes does not mesh well with the short-answer questionnaires favored in interviews.

V. There are also a number of 'strangeness factors' which affect any rural migrant to an urban area. Getting to a public facility may pose formidable transportation problems and necessitate travel in unfamiliar, discomforting areas of the city. Indian clients may not be aware of the services available to them. The unfamiliar and at times unpleasant interview procedures compound and may cause the attitudinal barriers discussed previously. 
The attitudes social services agencies have toward Indians, and most importantiy, toward Indian alcoholics, affect the success or failure an Indian person has in dealing with these agencies. Terry's being forced into coming to the rehabilitation clinic may be a factor in the program's lack of success with him. He has probably become very defensive and stubborn, which does not put him in the proper mood for recovery. His past experiences, bad or good, follow him to the next agency. Lack of trust and his demand to be treated immediately will have a negative effect on future treatment. 20

At most agencies, the staff takes on an attitude of delivering punitive casework, blaming the victim. They avoid understanding the complexities of causative behavior and emotional drives and concentrate on helping, and sometimes forcing, the client to 'face' his current reality problem. 21

A possible alternative for Terry Dakota would have been to place him in an Indian group home, had such a program been operational. A group living situation as proposed in this project would give the individual more outside support systems. It would also provide a communal home where a juvenile could live with his peers and would allow him to go outside the facility to be with his peers. This enables the youth to feel that he is not alone, thus providing reassurance. In the hypothetical case history, treatment of Terry's alcohol problem, as

20Statement by Maloney, Jet, (M.D.): Chemawa Indian School, January, 1977. In a discussion with Dr. Maloney, he explained how certain social service agencies fail.

${ }^{21}$ Annette Garrett, Modern Casework: The Contributions of Ego Psychology, Ego Psychology and Dynamic Casework, pp. 44-45. 
approached by standard social casework philosophies, was treated as the problem, not as a symptom of his true underlying probiem as it should be. A combination of traditional native interaction and modern intervention would enable Terry to deal with his problems one at a time.

\section{Theoretical Framework}

The preceeding case history contributes three major concepts upon which the model presented in Chapter II tests: the concept of fragmentation of the individual, or conversely the holistic treatment of the individual, the concept of al ienation in a diverse society, and the socialization process.

Holistic. Traditionally, institutional interaction is typified by compartmentalization. ${ }^{22}$ In non-Indian society the health clinic is concerned with health, the bank with financial status, and schools with education. In few instances is there a concerted effort to view an individual as a total entity representing a network of intertwining variables. That an individual is relating on one plane does not exclude the influences of his total life system. Therefore, to insure a relevant transaction at least an awareness of the breadth and scope of human diversity must be built-in both institutionally and programatically. As an example, a student who is not performing well in school may be hampered by financial problems hindering him from a full commitment to school. Without knowledge of outside circumstances, the student is misjudged and may lose the opportunity to pursue his education.

22Joseph S. Gallegos, Cultural Pluralism in Higher Education: A Case Study. Unpubl ished paper, 1975. 
In line with the holistic concept, integration is a natural outcome. In an integrated sense, parts are seen as complimentary and valued as equally important components of a dynamic whole. Observation of the parts does not provide for the knowledge or the appreciation of the whole. ${ }^{23}$ Emphasis in the scientific or mechanistic view has tended to skew our societal perception of man and nature. An integrated process of traditional tribal socialization allows participants to acquire a balanced appreciation of varied modes of knowing. Humanities and technology (sciences) are seen as complementary and not opposing modes of knowledge.

The notion that is fundamental to the alternative living concept is that of family. The family refers to the bonds of kinship found in the nuclear family, in the extended family, and in the tribal community at large (tribalism-brotherhood). ${ }^{24}$ on the one hand, it is the family which is the milieu in which an individual life system occurs. It is the family that supports that network. It is the family that set the stage for a holistic world view. The family integrates life experiences. The family is the tribe.

Peer support is a vital component of the alternative living system. The youth is seen as part of the alternative living system family and viewed as a total person. Upon entering the home, there is a constant monitoring to insure that the individual does not get lost. Upon acceptance, each youth is assigned a counseling team.

23Ludwig von Bertauffy, General Systems Theory, Brazalle, Inc., New York, 1968, p. 16.

${ }^{24}$ Miguel Montiel, "The Social Science Myth and the Mexican American Family," El Grito, Vol. 3, No. 4, Summer, 1970. 
Each team is composed of one staff person, one group ieader and a peer. The youth, himself, becomes an integral part of his own counseling team. This team remains as constant as possible throughout the entire placement process.

Alienation. Rejecting the melting pot theory of assimilation or amalgamation, it is the pluristic belief that a stronger nation will be formed when each cultural element is allowed to maintain its own institutions and beliefs. Only when full assimilation occurs can a minority group successfully disappear into the mainstream of life. With partial assimilation, alienation occurs within those aspects which differ widely. Alienation is directly correlated to the number of varying aspects. Cultural subtleties such as manners of speech, diet, personal space and temporal relationships are equally important AS RELIGIOUS AND EDUCATIONAL BELIEFS.

In foster care, a child supposedly replaces his natural parents with similar ones who will raise him with cultural mores, traditions, values, and social models useful to his development as a socially adjusted adult.

Socialization. Socialization is the process by which an individual belongs to a group. It is the purpose of socializing children to have them conform to the norms of a specific group. Traditionaliy this process is an oral tradition; tribally specific and convertly familial. Unless the child is surrounded by the group which he belongs by race and cuiture, he will not absorb these vital influences.

To spcialize the youth of a culturally minor element it is necessary to place them in a position of absorbing the influences of those 
who maintain a pluristic and holistic belief. Such influence would relieve the alienation of the youth in a society to which they are only partially assimilated. 


\section{HISTORICAL BACKGROUND}

In this chapter our purpose is to demonstrate what affect Publ ic Law 280 has on juvenile delinquency, in Indian country.

In 1963, the State Legisiature amended Chapter 240 Laws of 1957 with enactment of Chapter 63 Laws of 1963.

Assumption of criminal and civil jurisdiction by state. The State of Washington hereby obligates and binds itself to assume criminal and civil jurisdiction over Indians and Indian territory, reservations, country and lands within this state in accordance with the consent of the United States given by the act of August 15, 1953 (Publ ic Law 280, 83rd Congress, ist session), but such assumption of jurisdiction shall not apply to Indians when on their tribal lands or allotted lands within an established Indian reservation and held in trust by the United States or subject to restriction against al ienation imposed by the United States, unless the provisions of RCW 37.12. 021 have been invoked, except for the following:

(1) Compulsory school attendance

(2) Public assistance

(3) Domestic relations

(4) Mental Illness

(5) Juvenile del inquency

(6) Adoption proceedings

(7) Dependent children, and

(8) Operation of motor vehicles upon the public streets, alleys, roads, and highways: Provided further, that Indian tribes that petitioned for, were granted and became subject to state jurisdiction pursuant to this chapter on or before March 13, 1963 shall remain subject to state civil and criminal jurisdiction as if chapter 36 , Laws of 1963 had not been enacted.

In this act, the state asserted that it would assume civil and criminal jurisdiction over non-Indians on fee lands, and it assumed jurisdiction over Indians with respect to the eight listed categories on all non-fee lands. 
A title in 'fee' or in 'fee simple' is a full and absolute estate beyond and outside of which there is no other interest or even shadow of interest; it is an indefeasible title or estate in which is blended right of possession and right of propriety. 25

Non-fee lands are lands in which the federal government retains an interest. No charge was made affecting state jurisdiction over tribes which had ceded jurisdiction to the state prior to adoption of this act.

This act was declared to be unconstitutional by the 9 th circuit court of appeals on March 22, 1977. The court concluded that jurisdiction based on Tand title was a denial of equal protection under the law. (Confederated Bands of the Yakima Tribe vs State of Washington, et. a1., 9th Circuit Court of Appeal's, April 29, 1977.) A petition for a rehearing is currently pending so this decision is not yet final.

\section{Problem Statement}

Lack of clear jurisdictional authority, a problem for many years, has resulted in ineffective law enforcement and the inability of the Tribal court to properly prosecute young Indian offenders which in turn has contributed to disrespect for law and order.

The Native American youth and adults are unable to cope with the problems and frustrations of the real world in which apathy, prejudice, and discrimination present obstacles to the process lending to community integration. Caught in a seemingly hopeless situation in which a reservation sub-culture is in conflict with the culture of the dominant 1953).

25Publ ic Law 280, (83rd Congress, 1 st session, August 15, 
society; residing on a reservation where the disintegration of the Indian culture has left a cultural void; filled by family neglect; and required to exist in a world of dependency, they have refused to accept the norms and mores of society. ${ }^{26}$ These factors and others contribute to a deep sense of inadequacy, hostility, and disrespect for law and order.

These attitudes are manifested by the anti-social behavior of the youth and young adults today. There is strong evidence to indicate a competitive atmosphere among juveniles to become the most delinquent. 27 The youth who can create the most havoc is not looked upon with disfavor, but is upheld by his peers, and excused by his parents and other adults.

Native American suicide rates are 3 times and sometimes 10 times the national average. 28 The devastating effects of alcohol and/or drug abuse have touched many Native American families, which has contributed heavily to Native American family breakdowns, often resulting in youth incarceration.

Few rehabilitative services are effectively del ivered to them. Traditional educational, health, and social service facilities have been unsuccessful in meeting the special cultural needs of Native American youth. 29

There has not been a program designed to help reduce the

26 "Juvenile Del inquency Among the Indians," Interim Report of the Subcommittee to Investigate Juvenile Del inquency to the Committee on the Judiciary, 84th Congress, First Session, 1955.

$$
\begin{aligned}
& 27 \text { Ibid. } \\
& 28 \text { Ibid., p. } 30 . \\
& 29 \text { Ibid., pp. } 15,18,19,32, \& 115 .
\end{aligned}
$$


delinquent behavior of the resident youth and assist the youth's entire extended family for better relationships with each other and with all elements in the environment. A program is needed to incorporate services to all members of the Indian youth's nuclear and extended families. These are documented objectives. 30 If we wish to meet these more effectively, the following model seems more appropriate.

\section{Project Proposal}

The proposed program is designed to operate in close conjunction with the tribal Juvenile Probation offices in the selected region. Historically, the state has assumed jurisdiction over juveniles living within the boundaries of Indian reservations in the 11 states affected by Public Law 280. However, a May 1977 ruling by the 9th Circuit Court of Appeals has upheld the right of the Yakima Tribe to assume jurisdiction over eight areas, including juvenile offenders. This ruling, if upheld by the Supreme Court, will drastically alter the situation of tribes in states affected by Public Law 280 . It will mean that the tribes will regain exclusive jurisdiction over their juvenile offenders.

The program will provide alternatives for Indian youth and will most likely operate from a facility on a reservation in a state affected by Public Law 280. It is intended to assist State Juvenile Courts and probation offices within the selected geographic reservation areas in dealing with the increasing problems of Indian juvenile offenders.

30 Ibid., p. 45 . 
The proposed program will allow for the creation of a residential treatment facility for the diagnosis, placement, and treatment of Indian juvenile delinquents who are referred by the appropriate agency or court.

The proposed program will establish reporting and operating procedures with the various courts in order to integrate the treatment program with the courts' wishes.

The program is designed not only to help reduce the del inquent behavior of the resident youth, but to help the youth's entire extended family form a better relationship with each other and with all the elements in the environment. The Program will incorporate services to all members of the youth's nuclear and extended families.

The proposed program is designed to intervene in the activities of Status Offenders and recidivists and to divert them from the juvenile justice system by developing realistic and workable treatment techniques for the Indian youth and others of significance involved in the crisis.

The program will uncover alternate residential resources heretofor untapped for Native American youth.

The program will become a child-placing agency not only for Native American youths and their families who are directly involved in the program but for Native American youths who are in need of alternative living situations.

The proposed program will incorporate traditional Indian values and beliefs as a component of the treatment methodology. Efforts will be made to find positive problem solving methods 
that will enable Indian youth to cope with problems rather than removing the youth from the problem. 


\section{CHAPTER III}

\section{A MODEL FOR CHANGE}

Change Postulate No. 1:

The basis for rehabilitation is self-diagnosis of inadequacy. In the case of delinquents or status offenders, this means they have to come to the point of questioning the adequacy of their present adjustment. It is extremely important to note that this diagnosis cannot be made by other people, al though it must come about through collaboration with others. The unfortunate situation in correction at present is that the diagnosis is typically made by treatment personnel or administrators, often ignoring the perceptions of the persons or group upon whom the diagnosis is made. Not only are the individual's perceptions ignored, but the culture and the individual's position in that culture may likewise be ignored. This failure to acknowledge the influences of one's culture may have serious negative implications for the Native American youth. Thus, any juvenile diversion program intended for Indian youth must acknowledge and support the individual's cultural identity, while at the same time de-emphasizing those aspects of the youth's past life experiences which led to his/her del inquent behavior.

Because one's feelings of adequacy are based on confirmation by others that (s)he is an object of value, the extent to which a person will diagnose his/her behavior as inadequate will vary with the degree of insecurity he/she feels. As Lewin suggests, a person will maintain 
their loyalty to their old values and beliefs (delinquent) and their hostility to a new set of values (conventional) so long as they receive cues, confirming the adequacy of their present adjustment. 31 These cues, of course, must come from persons considered significant and important.

Change Postulate No. 2:

The maintenance of social relationships, roles and self-images stems from communication and represents the greatest force against change or diagnosis of inadequacy. The basis of group solidarity and organized activity is the flow of cues (verbal or non-verbal) indicating proper regard for each other. A person's values and beliefs are learned in and supported by a social context through the information received from significant others. Without inter-personal cues from others, one soon finds it impossible to maintain checks on his/ her own behavior and he/she becomes socially al ienated. It is in this condition, where the social supports are removed or destroyed, that persons or groups become susceptible to change. The degree of willingness to change is dependent upon the degree of social alienation. Thus, rehabilitation will be successful only if there is a concomitant change of sufficient nature in the delinquent culture with which the person identifies.

Change Postulate No. 3:

People are characteristically resistant to change. Bach states

${ }^{31}$ Kurt Lewin, Resolving Social Conflicts; Selected Papers on Group Dynamics, Gertrude W. Lewin (Ed.), New York: Harper \& Row, 1948. 
that the apparent reason for a patient to come in, is to be cured. Actually, the patient does not come to be cured; he comes to be approved, as is. Lippit, Watson, and Westly also state that opposition to any kind of change is likely to occur at the beginning of the change process. 32 Therefore, it might be argued that even voluntary patients fantasize and indeed seek approval for themselves as they are. It would be expected that involuntary patients (juveniles) would therefore demonstrate greater resistance to change because (1) they receive group support for their antisocial conduct and would thus not tend to diagnose their adjustment as inadequate; and (2) they are a captive group, forced to attend treatment sessions which may heighten their hostility toward the new model for living and greatly increase resistance.

\section{Change Postulate No. 4:}

Lewin suggests that since rehabilitation aims to change a system of values, resistance to change is expected and therefore change must be forced on the individual or group from outside sources. 33 This would be true of both voluntary and involuntary groups. The objective, then, is to create situations which would force group members to collectively question the adequacy of their adjustment, which is a way of forcing change upon the group.

Accordingly, when the anxiety level is high, there is reason to believe that the person or group is indeed questioning the adequacy

32R. Lippit, J. Watson, and B. Westley, The Dynamics of Planned Change, A Cooperative Study of Principles and Techniques, New York, 958.

33Lewin, 0p. Cit. 
of their current mode of operation. When ambiguous situations present themselves, group members find their past experiences ineffective in providing confortable structure. Thus, the new and ambiguous situation calls for a new mode of behavior and necessitates a collective diagnosis of inadequacy.

\section{Change Postulate No. 5:}

The acceptance of a new set of values is linked with the acceptance of a specific group. This offers some explaination for the high rate of recidivism characteristic of most correctional agencies. Perhaps treatment people have attempted to change the value systems without recognizing the inter-connections between a given set of values and a specific group. It may be necessary for a person to first accept a group before he can accept the group's values. ${ }^{34}$ A little different way of stating this same idea is that in the process of changing attitudes of hostility for a new system of values based on friendliness, persons must be placed in a situation which permits them to discover these new values for themselves. Only then will new values become their values, as opposed to others' values. Lewin points out an individual will believe facts he himself has discovered in the same way that he believes in his group or himself. 35

\section{TREATMENT PHILOSOPHY}

Shorn of the protective network of Indian tribal mechanisms, denied of the richness of Indian heritage and background, inured to

$$
\begin{aligned}
& { }^{34} \text { Lewin, Op. Cit. } \\
& { }^{35} \text { Lewin, Op. Cit. }
\end{aligned}
$$


parents and adult relatives who have been unable to establish concrete linkages to existing service organizations, Indian youths often resort to del inquent activities and behavior. Alternatives for Indian youths will be operating on the premise that Indian adolescent anti-social, pre-del inquent and del inquent behaviors are generally reflective of a breakdown not only of family solidarity, but of supportive extended family support system that may have been lacking in the youth's environment.

The Native American youths who arrive at our doors will be looking for concrete indications that they themselves as Indian people can survive with dignity, substance, and integrity. Our group home program guarantees that they will find it; that these opportunities for positive growth and acquisition of the Indian values and Indian self-identity can be consistent with functional behavior.

The incorporation of cultural consultants--tribal elders, medicine people, Indian arts and crafts experts, Indian community leaders, etc.--who will help the youths build a foundation with their ethnicity, and the predominance of Native American group home staff who will provide positive role images are important components of this group home program. In learning to identify with the positive aspects of Indian culture, as opposed to the stereo-typed negative aspects such as drunkeness, low scholastic records, high suicide and del inquency rates, being dirty, sloppy, poor, etc., the youth's concepts of self-values will be enhanced and will result in a reduction of anti-social behavior.

Alternatives for Indian youths is a comprehensive and multifaceted program, which is equipped with in-staff counseling, recrea- 
tion, school ing and spiritual guidance, as well as community-based Indian supportive systems from the selected Indian community: vocational and employment services, alcoholism counseling, and other Native American programs.

As with established social service agencies, our basic philosophy is that mental and physical health are directly related, and that treatment of one is not feasible without the corresponding treatment of the other. Alternatives for Indian youth would be an extension of the' comprehensive health services provided by the Indian community and the social services programs operated by the selected tribe. The group họe staff will provide direct counseling services and coordinate all phases of the youth's treatment program including schooling, spiritual guidance, recreation, vocational interests, etc.

Our program is designed not only for our youth residents, but for the youth's families, and will thus have an effect on all members of the large extended Indian family. As Native American birthrates are increasing, and as the average Indian family size is much greater than those of non-Indians, our successful treatment of one youth will result in the stabilization of the lifestyles of four or five full and half-siblings and to a lesser extent of about a dozen of the adolescents in his extended family. Our group home capacity is 20 youths. Statistically projected, with our outreach and follow-up counseling services, we will be working with an average of 15 youths and 8 adults for each youth resident served.

Our treatment philosophy hinges on individual accountability for behavior. Every effort is made to avoid relieving youth of the 
responsibility and burden of making decisions and managing his own life. We support the notion that each youth should have the privilege/ burden of participating in decisions affecting his life. We thus hold the view that removal of an Indian youth from society necessitates, under the best circumstances, a break in the sequence of personal responsibility and, therefore, should be as slight as possible. Ultimately, it is an Indian youth's adjustment in the community and not in the treatment setting which is of primary concern to our program. Program activities (e.g., group and family counseling, participation in school, work, athletics, residential living and ongoing community exposure while in placement) are thus geared to provide realistic, dynamic, and transferrable experiences.

At the very core of our treatment philosophy is the idea that Indian youth can control and govern themselves if provided with effective guidance and direction. Furthermore, imposed decision-making from authorities (staff) serves to relieve Indian youth of being accountable and actually encourages them to abdicate all responsibility for controlling their (or their peer's) behavior towards adults. Consequently, decision-making must become a collective process whereby the knowledge, skill, and experience of the youth, his peers, family and staff is utilized. Group living, then, is viewed as an ideal medium for increasing self-esteem, personal knowledge and understanding of others.

Emphasis on the collective decision-making process requires our staff and each of the young people in residence to individually tailor a program for each youth. Since each person is unique, with different needs and treatment goals, individualized programming is essential. 


\section{PROJECT INTENT}

\section{Goals/Objectives/Tasks: An Introduction}

The overall goal of this program is to intervene in the lives of children and youth who are recognized as being delinquent and by utilizing all community resources to re-direct these del inquent youth. To improve prevention and control of juvenile delinquency by developing and by coordinating all branches of community services designed to divert potential del inquents from the juvenile system. To improve programs, if any, on the selected reservation or establish a juvenile status offender program.

The overall program objective of the program is to divert juvenile delinquents and potential delinquents from the juvenile justice system and establish follow-up programs that will reduce recidivism among delinquents and crime on the selected reservation.

Tasks:

-Aid the community in detecting the potential delinquents and diverting them from the juvenile justice system.

-Provide for intervention in del inquent behavior by removing or correcting sources contributing to juvenile delinquency. -Involve the delinquent in selected community programs designed to prevent delinquency.

-Assist parents and schools of the selected reservation area to identify the potential delinquents.

-Provide casework and follow-up services for those identified as ajudicated del inquents. 
-Develop innovative and effective programs and coordinate all community resources designed to divert del inquents from the juvenile justice system.

Goal I: To improve the future outlook for Native American peoples through establishing and implementing Indian-based social services programs.

Objective: To reduce youth incidents of del inquent behavior at threemonth intervals. At the end of a calendar year of a youth's residency, or at the time of his discharge if sooner than a year, his/her del inquency record during the time of his residency will be compared with his record for the year(s) prior to his/her admittance to this program.

Tasks:

-Establish contracts on dacility and equipment acquisition and development of community resources for equipment and supplies. -Establishment of screening criteria, screening committee for interviewing; and accepting or referring applicants.

-Meeting state 1 icensing requirements.

-Development of reporting structure and filing system to meet requirement of funding sources.

-Recruiting, screening, hiring and training of group home staff. -Staff and youth orientation program.

-Evaluation of each admitted youth's educational and vocational needs.

-Placement and enrollment of youth in educational program and coordinating with schools for progress and scholastic achievement reports. 
-Quarterly progress reports to youth's referring agency(s) to the juvenile courts, and to funding sources.

-Evaluation of health, mental, physical, and emotional and assessment of youth need.

-Operate a residential treatment facility for anti-social youth. Goal II: To promote self awareness and Indian values as a means of gaining self-pride, and cultural identity, in the alleviation of the stresses that become factors in the youth's anti-social and del inquent behavior.

Objective: To incorporate parent, relative, and family need into the youth's treatment program. Referrals will be made to appropriate supportive services within the selected tribe's social, health, educational and counseling services and progress reports will be received from these programs.

Tasks: Establish contracts with parents, relatives, and significant others, encourage participation in youth's treatment program, and referral to appropriate supportive services.

-Establishment of and implementation of individualized treatment program for each youth with monthly and quarterly goals. -To provide cultural bridges between the past, present, and future Native American youths, so that Native American youth need not resort to anti-social behavior but can participate in culturally revelent activities.

-To improve the mental, physical, and emotional health of Native American youths and families with a focus on resolving cultural and behavioral conflicts, to help reduce the youth's negative response to these conflicts. 
Goal III: To reunite Native American families, whenever possible, and to find substitute extended family support systems for those youth with no identifiable family ties, and to strengthen the family fabric, and to support the extended Indian family institution, so that youths can be given constructive guidance from the adults in their family. Objective: To project positive Native American images through group home staff and cultural consultants. Youths will fill out forms and write short essays quarterly, on the subject "What it means to be Indian". The cultural relevancy of this program will be evaluated through youth's positive and negative responses to this program. Tasks: Develop community based resources and services to expand the treatment capabilities for youth in the program.

Goal IV: To improve youth's school achievement and academic programs and the amount of youth participation in school-related activities. Objective: One important measurable objective is to raise the grade level of each youth, vis-a-vis one year for each semester in the Indian education program offered by the group home.

Tasks: Pre and post comparisons will be made.

NATIONAL STANDARDS AND GOALS 36

Standard 16.9

Detention and Disposition of Juveniles:

Each state should enact legislation by 1975 limiting the delinquency jurisdiction of the courts to those juveniles who commit acts

36 National Advisory Commission on Criminal Justice Standards and Goals Correctives, U.S. Government Printing Office, Washington D.C., p. 567-580. 
that if commited by an adult would be crimes. The legislation should authorize a wide variety of diversion programs as an alternative to formal adjudication. Such legislation should protect the interests of the juvenile by assuring that:

1. Diversion programs are limited to reasonable time periods.

2. The juvenile or his representative has the right to demand formal adjudication at any time as an alternative to participation in the diversion program.

3. Incriminating statements made during participation in diversion programs are not used against the juvenile if a formal adjudication follows.

Standard 16.7

Sentencing Legislation:

Each state, in enacting legislation (as proposed in Chapter 5) should classify all crimes into not more than 10 categories based on the gravity of the offense. The legislature should state for each category, a maximum term for State control over the offender that should not exceed 5 years--except for the crime of murder and except that, where necessary for the protection of the public, extended terms of up to 25 years may be imposed on the following categories of offenders :

1. Persistent felony offenders

2. Dangerous offenders

3. Professional criminals

The legislation should contain detailed criteria patterned after Section 7.03 of the Model Penal Code as adapted in Standard 5.3 defining the above categories of offenders. 
Standard 16.8

Sentencing Alternatives:

By 1975 each State should enact the sentencing legislation proposed in Chapter 5, Sentencing, reflecting the following major provisions:

1. All sentences should be determined by the court rather than by a jury.

2. The court should be authorized to utilize a variety of sentencing alternatives including:

a. Unconditional release

b. Conditional release

c. A fine payable in installments with a civil remedy for nonpayment.

d. Release under supervision in the community.

e. Sentence to a halfway house or other residential facility located in the community.

f. Sentence to partial confinement with liberty to work or participate in training or education during all but leisure time.

g. Imposition of a maximum sentence of total confinement less than that established by the legislature for the offense.

3. Where the court imposes an extended term under Standard 5.3 and feels that the community requires reassurance as to the continued confinement of the offender, the court should be authorized to: 
a. Recommend to the board of parole that the offender not be paroled until a given period of time has been served.

b. Impose a maximum sentence to be served prior to eligibility for parole, not to exceed one-third of the maximum sentence imposed or be more than three years.

c. Allow the parole of an offender sentenced to a minimum term prior to service of the minimum upon the request of the board of parole.

4. The legislature should delineate specific criteria patterned after the Model Penal Code for imposition of the alternatives available.

5. The sentencing court should be required to make specific findings and state specific reasons for the imposition of a particular sentence.

Standard 16.9

Detention and Disposition of Juveniles:

Each State should enact legislation by 1975 limiting the delinquency jurisdiction of the courts to those juveniles who commit acts that if comitted by an adult would be crimes.

The legislation should also inciude provisions governing the detention of juveniles accused of del inquent conduct, as follows:

1. A prohibition against detention of juveniles in jails, lockups, or other facilities used for housing adults accused or convicted of crime.

2. Criteria for detention prior to adjudication of delinquency matters which should include the following: 
a. Detention should be considered as a last resort where no other reasonable alternative is available.

b. Detention should be used only where the juvenile has no parent, guardian, custodian, or other person able to provide supervision and care for him and able to assure his presence at subsequent judicial hearings.

3. Prior to first judicial hearing, juveniles should not be detained longer than overnight.

4. Law enforcement officers should be prohibited from making the decision as to whether a juvenile should be detained. Detention decisions should be made by intake personnel and the court.

The legislation should authorize a wide variety of diversion programs as an alternative to formal adjudication. Such legislation should protect the interests of the juvenile by assuring that:

7. Diversion programs are 1 imited to reasonable time periods.

2. Detention, if imposed, should not be in a facility used only for housing juveniles who have committed acts that would be criminal if committed by an adult.

3. Detention, if imposed, should not be in a facility used only for housing adults accused or convicted of crime.

4. The maximum terms, which should not include extended terms, established for criminal offenses should be applicable to juveniles or youth offender is processed through separate procedures not resulting in a criminal conviction. 
Standard 16.11

Probation Legislation:

Each state should enact by 1975 probation legislation (1) providing probation as an alternative for all offenders; and (2) establishing criteria for (a) the granting of probation, (b) probation conditions, (c) the revocation of probation, and (d) the length of probation.

Criteria for the granting of probation should be patterned after Section 7.01 of the Model Penal Code and should:

1. Require probation over confinement unless specified conditions exist.

2. State factors that should be considered in favor of granting probation.

3. Direct the decision on granting probation toward factors relating to the individual offender rather than to the offense.

Criteria for probation conditions should be patterned after Section 301.1 of the Model Penar Code and should:

1. Authorize but not require the imposition of a range of specified conditions.

2. Require that any condition imposed in an individual case be reasonably related to the correctional program of the defendant and not unduly restrictive in his liberty or incompatible with his constitutional rights.

3. Direct that conditions be fashioned on the basis of factors relating to the individual offender rather than to the offense committed. 
Criteria and procedures for revocation of probation should provide that probation should not be revoked unless:

1. There is substantial evidence of a violation of one of the conditions of probation;

2. The probationer is granted notice of the alleged violation, access to official records regarding his case, the right to be represented by counsel including the right to appointed counsel if he is indigent. The right to subpoena witnesses on his own behalf, and the right to confront and crossexamine witnesses against him. 


\section{PROJECT IMPLEMENTATION}

\section{Operational Methods}

Screening of referrals--demographic information, behavioral assessment, interview with youth applicant as well as with his/her parents, relatives, and significant others, referring agency statement of precipitating problem, incidents of delinquent behavior and activities.

Admittance procedures--youth assessment, written assessment from referring agency, parental assessment, physical examinations, school records and grade placement, etc.

Orientation of youth to program--introduction to group home staff and program, formation of individualized treatment plan, development of group treatment plan and goals, familiarization with supportive services.

Education--required attendance and participation in a) a regular public school program, b) at an Indian school, if available, or c) classed at group home with certified teacher. Tutorial, advocacy and liaison services through counselors as needed. Vocational guidance and training.

Health--ongoing services from Indian Health Services, including mental health and psychological consultive services. Nutritional program. Drug and alcohol awareness counseling from an established 
Indian drug and alcohol program if available.

Social services--group, family and individual counseling, cultural consultants, medicine people, arts and crafts instructors, organized and individual sports, recreational activities and outings, positive projection of Native American images through staff, consultants, medicine people and volunteers. Workshops on Indian lifestyles, culture, customs, and traditions. Referral to supportive services, whether individually or with family.

Supportive services--based on behavioral therapy concepts with culturally relevant methods of helping Indian youths achieve treatment goals. Stress on 'competing behaviors' concepts, that is, to occupy the youths time with constructive behaviors and activities that cannot be performed concurrently with unacceptable or destructive behaviors.

Spiritual guidance--discussions of Indian reverence of nature, Mother Earth, sharing of knowledge with tribal elders, respect for all living things, protection of natural resources. Attendance, if desired, of the church of the youth's choice.

\section{Relationship to Tribal Juvenile Courts}

The project: Alternatives for Indian Youth will be operated in close conjunction with the tribal Juvenile Probation Offices in the selected region. Historically, the state has assumed jurisdiction over juveniles living within the boundaries of Indian reservations in the 11 states affected by Public Law 280. However, a May 1977 ruling by the 9th Circuit Court has upheld the right of the Yakima Tribe to assume jurisdiction over eight areas, including juvenile offenders. This ruling, if upheld by the supreme court, will drastically alter 
the situation of tribes in states affected by P.L. 280 , over it's juvenile offenders.

As is currently envisioned, the Tribal Juvenile Court Director will screen and hire the Executive Director for the program once it is funded. The same Juvenile Court Directors will sit on an advisory committee to the non-profit corporation, advising on matters of policy, intake, treatment, reporting, and procedure. It is quite likely that one of the Juvenile Court Directors will sit on the non-profit corporation's Board of Directors.

It may be simply stated that the intention of this project will be to provide alternatives for Indian youth who are in trouble. The vehicle of the Tribal Juvenile Courts in the state is seen as the most viable (and helpful) option fulfilling that intent.

Program Financing

This project will provide alternatives for Indian youth and will most likely operate from a facility on a reservation in a Public Law 280 state. The intent is to increase its capacity to be able to house and treat up to 20 youths who are referred from the Tribal Juvenile Courts as juvenile delinquents or dependents. The financing picture is rather simple:

1) Funds from the Juvenile Del inquency Act through the Bureau of Indian affairs will be used mainly for capitol outlay, e.g., equipment and remodeling.

2) Operational and overhead costs will be covered through the Department of Social and Health Services on a periodic basis as a voluntary child care agency. A monthly reim- 
bursement level will be established which should cover general operations, medical, and child maintenance costs.

At least $90 \%$ of the costs will be reimbursed by DSHS.

3) Outside revenues can be expected from Tribal resources, B.I.A. and other sources.

\section{Description of Clientel}

The plan for service improvement for Indian youth who are in need of alternative family living situations may be summarized in the following fashion: Del inquents.

Presently, the plan calls for the development of one cottage home for 20 Indian youth, 13-18 years of age, who are adjudicated del inquents. This institution will operate within the region and offer the following kinds of aspects:

1) Stable controlled residential setting.

2) Productive learning environment.

3) Reliable diagnostic and testing capability.

4) Viable treatment modalities.

5) Proper tie-in to community resources for program improvement.

6) High quality relationship with the state's reservation Tribal Courts.

7) Sound evaluation and monitoring capability.

8) Crisis intervention capability.

9) High level in-service training for staff and other criminal justice system officials.

10) Lower social, economic, and human costs of juvenile progress. Presentiy this element of the plan is still in the nego- 
tiating stages.

\section{Description of Services}

A. Professional services:

1) Group counseling: All youth participate daily in smal1 group discussions where the focus is on 'here and now' material.

2) Individual counseling: This is designed to be compatible with and complement the group counseling approach.

3) Family counseling: Families of Indian youth in residence are urged to participate in family group counseling sessions. Family counseling services are extended to assist in re-integrating the youth back into his/her family and community.

4) Psychiatric service: Diagnostic services as well as ongoing psychiatric consultation is available to those youth exhibiting emotional and mental stress. The use of traditional medicine men in psychiatric work shall be implemented.

5) Medical and Dental Services: Will be contract services; physical examinations will be mandatory.

B. Educational Program:

Each referral will have his/her education history, development and current status evaluated and our staff will work directly with schools involved.

C. Work Experience:

Where applicable, community resources will be used (i.d., Job 
Corps, etc.)

D. Residential Living:

Return to home, foster home, or other suitable placement will be primary direction for counselors.

E. Recreational Activities:

Community services will be used.

F. Religious Instruction:

Traditional tribal community services will be used.

G. Post Release Services:

In an effort to assist Indian youth in establishing linkage to their families and communities, youth may return to discuss, with their families present, their community and home adjustment. H. Foster Care:

Screening, training, and follow-up formal training sessions will be held for all foster parents. The "Alternatives for Indian youth Program" will be a primary resource for foster parents. I. In-Staff Training:

Will be open to child care workers, parole officers, and other interested parties, formal sessions of 8-16 hours a week focusing on:
a) The juvenile justice system;
b) Traditional tribal teaching;
c) Child development;
d) The group nature of del inquency;
e) Family/ extended family parenting effectiveness skills development.

\section{Staffing Nature and Patterns}

The program will be headed up by an individual selected by the Tribal juvenile court directors in the area. This person will serve as the executive director for the non-profit corporation which will, 
among other duties, operate a status offender program and residence. As the program is oriented to the Indian people of this state, preference will be given to those who have the outlined qualifications. The reason for the emphasis on Indian personnel is the great importance placed on traditional Indian life-styles and the promotion of Native American culture. The staff necessary for the program is as follows: Executive Director - This person will be responsible for the overall direction of the project. He will manage and supervise the overall project's activities. He will report to the Board and be responsible for fiscal and monetary activities.

House Manager - This person will be responsible for the day to day operation of the facility, the custody and control questions, educational, vocational, athletic, social, and counseling activities. He will report directly to the Executive Director.

Supervising Counselor - This position will be filled by an Indian whip man who will supervise the counselors and provide guidance to all staff. He will be responsible for providing spiritual direction to the program as well as arranging traditional ceremonies and recruiting community elders as guest speakers. He is accountable to the Executive Director for all treatment and maintenance functions of his program including the promotion of Native American culture. Counselors - These will be responsible for the youth in the program. They will set up and organize daily activities with the youth in the program. Those day to day activities normally associated with house parents will also fall under the duties of these positions. They will report directly to the supervising counselor. 
Secretary - Who will perform normal clerical and secretarial functions. Will report directly to the Executive Director.

Bookkeeper - Who will keep and maintain all fiscal and monetary records for accountability to the Board and to the staff. This position will report directly to the Executive Director.

Maintenance Person - Who will keep up the building and the grounds on a periodic and as necessary basis. This position will report to the Executive Director.

Relief Counselors - Will perform the same tasks as counselors during vacations, etc. Volunteers/Interns - Indian college students and community volunteers who will work with the community service aspect of the overall project. They will also serve as aides to counseling staff.

The ultimate objective of all staff persons is to function as active agents of change for program members. We make the basic assumption that the staff exists to help youth in trouble and, therefore, expect total commitment and openess to seek new treatment modes and use their experiences as growing points of departure for their own lives. Perhaps the most critical area of our program is a description of the general nature of our staff philosophy. All professional staff (counselors, etc.) work and live with the students on a 24 hour basis. In doing so, they are each concerned and must deal with all phases of the life circumstances of the cottage members. Of necessity, lines of authority are divided among the lines of education and experience of the staff members involved. Such support as we can receive from Indian graduate interns and Indian community 
volunteers is used at the discretion of the professional staff and will, of course, vary with needs and abilities of the students and volunteers.

\section{Cottage Structure}

Counselors must become proficient at building and maintaining a non-threatening, 'therapeutic' culture. If staff are timid about taking a strong firm stand (indicating assumption of a leadership role), who will give direction and control the cottage or the community? Obviously, the strong anti-social leaders will assume this function. It is possible for staff to abdicate leadership to the strong and articulate delinquent leaders and thus these may become the standard setters.

It is alright for a cottage to decide new and different procedures to accomplish a task but staff must set the standards and not accept.mediocrity. Staff cannot let a group neutrilize, explain away, or discard cottage structure or community structure (rules). Organizational stability and continuity must be established and maintained. Organizational needs, like individual needs, are important and need sustenance. If a group of youth (and staff) are asked to commit themselves to the pursuit of difficult and trying goals, (changing human behavior and attitudes) they must have confidence in the rutes which govern that pursuit, and must be reassured that others will play by the same set of rules. Otherwise, trust is undermined and the organization is weakened. To prevent this from occuring, steps must be taken to define basic ground rules which establish those kinds of behavior that would be required for continued member- 
ship in the organization.

NORM \#1. Physical violence or the threat of physical agression will not be tolerated.

NORM \#2. Individuals must accept the fact that they are placed here by the court and that this is a legal placement and therefore each individual must make the treatment program top priority in his/her life and become actively involved in the regular program, e.g., attending groups, participating in school, work, cottage life programs, etc. NORM \#3. Over time, there must be a decrease in anti-social behavior (boys and girls could not merely 'do time', that is, to adopt a cynical stance in which their only intent is to appear to conform without actually doing so).

Therefore, the maintenance of order and stability is essential and on occasion some coercion is necessary to reinforce the norms. It is hoped that coercion would be held to a minimum, but its use would not be without some redeeming features. The occasional imposition of temporary controls might actually be more successful in achieving an objective than if they were left totally unrestrained, even though they were continuing to get into trouble. A temporary reinforcement of ground rules is necessary to maintain norms, provide organizational stability and continuity, and to get boys and girls involved in the program.

EVALUATION AND MONITORING PROCEDURE

The goals for the project are to (1) establish an intensive residential treatment facility for Indian youth with an emphasis on 
traditional Native American values as an alternative to existing referral options exercised by the non-Indian juvenile justice system and (2) to provide intensive residential treatment for these youth in order to alter their subsequent del inquent behavior. The evaluation procedure recommended for implementation with this program will be based extensively on the work of Harry C. Springer, Ph.D.--in particular, his suggestions for evaluation procedures for group homes. 37

Method

Subjects. The project population will be comprised of Indian youth from age 13-18 who are referred to the project by the Juvenile Courts on reservations in Public Law 280 states for residential treatment. These will be youth who come before the courts as a consequence of being involved in a chargeable offense or by virtue of the filing of an incorrigability petition. Not more than twenty-five percent of the youth served will come to the project as a consequence of an incorrigibility petition.

A maximum of twenty youth will be served at the treatment facility at any given time. During the course of a calendar year as many as sixty youth are expected to enter the project program. Prior experience with similar programs (e.g., Boy's Republic of California) indicate that not all youth will progress through the entire program. It is anticipated that from 33 to 48 youth will complete the program and "graduate" (i.e., return to the community).

Procedure. Evaluation of the project will be defined under

37Harry C. Springer, Social Agency Referral Project: Program Efforts and Accompl ishments, Unpublished Manuscript, 1972. 
three major headings: effort efficiency, and impact. The specific data to be collected and reported will be identified under these headings. Where appropriate, statistical tests will be suggested.

Effort. The project staff will maintain records to identify the following:

a. Number of youth entering the program.

b. Characteristics of youth entering the program (e.g., age, tribe, reason for referral, prior del inquent contacts, etc.).

c. Status of youth in the treatment program in terms of numbers of weeks of treatment per youth.

d. Reason for termination from program (e.g., "graduation", termination for other reasons, etc.).

These data will be maintained and reported on a monthly basis or according to such other requirements as may later determine.

Efficiency. Consistant with the therapeutic model employed by the project, all youth will be identified by their "status" or "rank". Youth entering the program will be assigned a rank of "l". As these youth demonstrate approved of behavior they may improve their ranking until they achieve the highest rank of "4". As a prelude to "graduation" (to foster care and eventual reintegration into the community), youth will be required to maintain a rank of "3" or better for at least six consecutive weeks. Thus, approved behavior leads to improved ranking which, in turn, is reqarded with increased freedom while at the treatment facility and eventually, freedom to return to the community.

Movement from one rank to another is a product of group consensus--a unanimous decision reached by both project staff and other 
youth in the project program. While youth enter the program with a rank of "1", inappropriate behavior--as defined by the group--can lead to a loss of that rank thereby leading to a status of "0". In summary, the efficiency of the program can be monitored across time by assessing the status rankings of youth who remain in the program. These rankings range from " 0 " to "4". Although fluctuations in individual rankings may reasonably be anticipated as individual youth progress or decline in the status system from week to week, the over-all impact on youth collectively considered should be higher rankings as a function of time in the program. In this context, it is important to remember that status is directly linked to approval and accepted behavior.

In order to obtain this efficiency measure, the project will maintain an accurate record of the status of youth in the program. The preferred statistical techniques for assessing the extent to which youth have improved their status (behavior) across time is analys is of varience. $^{38}$ An equally acceptable and somewhat more sophisticated statistical test would be trend analysis. ${ }^{39}$ A less complex and less powerful statistic would be correlation coefficients. ${ }^{40}$

Sufficient time needs to elapse and a sufficient number of youth need to become involved in the project before the preceeding efficiency analysis can profitably be undertaken. A minimum of six months should

38Rupert G. Miller Jr., Simultaneous Statistical Inference, McGraw-Hil1 Book Co., New York, 1966, pp. 54-58.

39 Murrey R. Speigel, Ph.D., Schaum's Outl ine of Theory and Problems of Statistics, McGraw-Hil Book Co., New York, 1967, p. 221. 40 Ibid., pp. 243-246. 
be allowed before attempting to employ these analyses. Once that time has elapsed, project personnel will be provided with a useful tool to assess the extent to which youth are, in fact, modifying their behaviors in the expected direction.

Impact. As noted above, one of the goals of the project is to reduce subsequent delinquent behavior on the part of the youth who participate in the project. This goal has been translated into three specific objectives.

1. To demonstrate a statistically significant reduction in the number of youth who have subsequent contacts with the reservation courts.

2. To demonstrate a statistically significant reduction in the number of contacts by those youth who are engaged in subsequent criminal behavior.

3. To demonstrate a statistically significant reduction in the seriousness of such contacts as do occur by youth involved in the project.

Before proceeding with a presentation of the research design for impact assessment, three inter-related problem areas need to be identified and discussed. These three problem areas are: randomization and the use of a "no treatment" control group, the employment of muitiple treatment groups for comparison purposes, and the appropriate treatment for the treatment phase of the Project. Each of these problem areas will be considered, the specific problems identified, and potential solutions offered.

The first problem area relates to the requirement of "classical" research methodology that subjects be randomly assigned to either a 
treatment or a control group population. The control group is presumed to represent the same population as the treatment group and is also presumed to receive no treatment whatsoever. Translating these general requirements into framework of the reservation project, Juvenile court judges would randomly assign youth to the reservation project or to a "no treatment" status. Presumably this would mean return to the community for the non-treatment control group population.

To comply with the requirements of a classical research model reservation Juvenile Court judges would be required to relinquish both their right to choose what they deem the most appropriate assignment for an Indian youth and their judicial responsibility for making such choices. The reality of field-evaluation is: the judges cannot be expected to yield their most important responsibilities for the sake of research design. Beyond this, to assign youth whose behavior is serious enough to warrant court attention in the first place to a no treatment control group are not seen as feasible research prerogatives for the evaluation of the reservation project. A "second-best" alternative would be random assignment of Indian youth to specific types of treatment programs, among them, the reservation project. This alternative would permit comparisons between different types of treatments and provide a basis for evaluating the impact of the reservation project relative to these other existing alternatives. This method presents some problems too.

Recognizing that random assignment cannot be obtained, it would be still possible to salvage some of the benefits of multiple treatment comparisons. In this variation of the multiple-treatment comparisons model Juvenile Court Judges would retain the right and responsibility 
to assign treatments deemed most appropriate for a specific Indian youth. However, if data can be obtained regarding the Indian youth's contacts with the criminal justice system prior to the most recent court appearance, during the treatment program, and subsequent to termination of treatment some useful comparisons can still be made. The need for contact information prior to the most recent court appearance stems from a requirement to determine whether different Indian youth are assigned to specific treatment programs as a demonstrable consequence of the frequency and character of their prior (as well as most recent) criminal behavior.

It should be clear that a program or treatment option which is based only for the most (or least) serious offenders would be in either a highly disadvantaged or highly opportune position from a comparison standpoint. To illustrate this problem, if only the most seriously delinquent Indian youth are sent only to a group home placement situation, a comparison between the outcome for the reservation project and group home placements places the reservation project in a disadvantaged situation. To determine whether this situation obtains in reality, reservation project researchers would need to have access to the criminal history records for all male and female youth who come before the tribal juvenile court in the previous calendar year. Should access be given, researchers would compute the total number of offenses and the total seriousness scores for these offenses during the year prior to the referral to the tribal juvenile court. These comparisons would answer the question: "Are Indian youth sent to specific treatment programs significantly different from one another?." 
The statistical test for such comparisons would be $\dot{a} \underline{t}$-test or Duncan's New Multiple Range Test. 41 Indian youth would be grouped according to assigned treatments and group means for number and seriousness of prior contacts would be used as a basis for making the comparisons. Only treatment groups demonstrated to not be significantly different prior to treatment would be compared in the final project evaluation report.

The advantages for the above approach should be obvious. In addition to providing a basis for comparing the impact on Indian youth of the reservation project with the impact of other programs, the other programs themselves can be compared among themselves: Data can be supplied to determine whether or to what extent differential treatment modes are linked to either the number of prior criminal contacts or the seriousness of prior contacts.

As is often the case with feild-research, advantages are gained as a cost. Implementation of the multiple-treatment comparison research model is not problem fee. These problems are identified by the questions which follow.

1. Will Tribal Juvenile Court Administrators in the selected reservation area permit access to all records for male and female Indian youth who come before the court in the previous calendar year?

2. Will the reservation project administration provide the additional funds necessary to collect, record, review, analyze, and research the increased number of Indian youth records

${ }^{41}$ Miller Op. Cit., pp. 81-90. 
which would be generated by this research program?

An answer to the first question must be made prior to the implementation of the project. If the answer is affirmative and data recording procedures can be developed, it will be necessary to determine the number of Indian youth whose records are apt to be reviewed, based on projection from prior years and, given this information, determine the costs of implementing this research option. Until such time as these determinations can be made, this method of assessing the impact of the reservation project must be considered to be only one option: an option which provides maximum benefits in terms of research design and information analysis.

The precise methods for translating the reservation project program impact objectives into operational methodology will follow shortly. Prior to that, however, one final problem area needs to be reviewed. This problem refers to the appropriate handling of the treatment phase of the program. Since each of the treatment modes in a multiple treatment design involves a span of time during which "treatment" occurs, a simplistic pre-post test model of evaluation presents specific problems. There is a continuing uncertainty among researchers as to the proper handling of the treatment phase. With the possible exception of institutionalization, each of the treatment modes offers the Indian youth the potential for engaging in further criminal behavior. That is, youth while on probation or while in a group home or the projected facility are still potentially free to engage in further offenses during the "treatment" period. Another way of stating the same problem is, "When does the post-test (posttreatment) period begin?" 
For each comparison treatment mode it will be necessary to identify the specific point at which it may be said the "treatment" has concluded. In the case of institutionalization, for example, this would be the date of release from the institution. A similar standard would hold for project youth. The post-test period for youth would beg in at the time the youth are placed on probation. Group home youth would be in their post-test period at the time they either (a) entered the group home, or (b) returned to their family residence after being in the group home.

In summary, three problem areas have been identified. These are (1) the 1ack of a control group, (2) the use of a multiple-treatment model, and (3) the proper starting point for the post-test period analysis. The crucial area of concern revolves around access to records for Indian youth in treatment programs other than the project program. If these concerns can be resolved, the following research model--hereafter referred to as Option A--represents the most usefur and powerful design.

Option A: What follows are the specific steps needed to implement a multiple-treatment research model.

1. Assure identification of all the Indian youth who come before the Tribal Juvenile court in the selected reservation area. (Excluded will be Indian youth below the age of 13.)

2. Assure access to the criminal history of all Indian youth who meet the project population definition within the reservation area.

3. Assure availability of criminal history contact record data 
for three periods of time: (1) one year prior to the tribal court referral, (2) criminal contacts which occur during the "treatment" phase, and (3) criminal contacts during a one year post-test, after treatment phase. For purpose of this research, a "criminal contact" will mean any contact which eventuates a new court referral.

4. Based on previous years data, determine the total number of Indian youth who meet the project population definition within the reservation area.

5. Develop cost estimate for (1) data collection, and (2) research analysis efforts.

6. Establish costs estimates to assure adequate funds for evaluation.

7. As Indian youth come before the Tribal Juvenile court during the calendar year, record an acceptable identifier (not necessarily the youth's name unless assigned to the project), the number of prior tribal juvenile court contact's for that youth in the six and twelve month periods preceeding the court contact. This recording will include the contact which caused the youth to come before the court in the research and evaluation period.

8. Assign a Seriousness Score to each contact. A seriousness scale has been developed and used extensively in the Seattle and King County area of Washington State. This scale, the Springer Seriousness Scale (revised), assigns a numerical value ranging from 0 to 7 for specific types of criminal contacts. Most serious contact, those involving offenses 
against persons such as rape or murder, are assigned a value of "7". Least serious contacts, such as dog leash violations are assigned a low rating or a zero rating. Intermediate contacts such as vandalism, curfew violations, possession of stolen property and so on are assigned values from one through six. ${ }^{42}$

9. Establish procedures to assure that Tribal juvenile court contacts will be recorded and scored.

10. Initiate data recording and data analys is activities.

11. Initiate data analysis activities.

12. Submit final evaluation. The format for the final evaluation report, insofar as it speaks to impact evaluation will include the following data analysis:

a. Pre-test period comparisons for six or twelve month periods prior to court referral which caused the Indian youth to become identified as part of the project program evaluation population. Two comparisons will be made for each treatment model number of prior tribal court referrals and the seriousness of offenses which led to tribal court referrals. Where statistically significant differences appear between the independent variables (contact and seriousness) and the dependent variables (specific treatment method selected). These differences will be noted. Post-test data analysis will reflect an awareness of the differences and the 
consequences for data analysis and interpretation. The test to be used for this comparison will be Duncan's New Multiple Range Test.

13. Secure agreement regarding the proper definition of "treatment". Specifically for each treatment method, when will treatment be said to have begun and when will it be said to have ended?

14. Based on agreements reached regarding the proper definition of "treatment" evaluate the number of tribal court contacts and the seriousness of the offenses which led to the contacts during the treatment phase. Once again, two comparisons will be made (contact and seriousness) for all treatment methods using Duncan's New Multiple Range Test or a similar test can be used to assess the success of various project in terms of number's of Indian youth who have subsequent tribal juvenile court contact. Thus, the treatment phase analysis will address all three project objectives: number of Indian youth, number of tribal juvenile court contacts by Indian youth who do have contacts, and the seriousness of contacts.

15. Given agreement on a definition for the end of "treatment", analysis of the number of Indian youth who have contacts, the number of contacts, and the seriousness of contacts for a year post-test period. Analysis of these data will be done by using Duncan's New Multiple Range Test and Scheffe's 
Test for Multiple Comparisons ${ }^{43}$ or other tests judged to be relevant to Indian people.

The evaluation model which has been proposed can be illustrated. Figure 1 summarizes both the types of treatment groups which might be considered and the treatment periods. An Indian youth becomes identified as part of the project population at Observation 3 when he appears before the court. At that point a decision is made regarding the appropriate treatment method. In addition, the Indian youth's prior court contacts in a period of six months $\left(\mathrm{O}_{2}\right.$ to $\left.\mathrm{O}_{3}\right)$ and twelve months $\left(\mathrm{O}_{1}\right.$ to $\left.\mathrm{O}_{3}\right)$ are recorded and scored for seriousness. The second analys is covers the treatment period from $\mathrm{O}_{3}$ to $\mathrm{O}_{4}$ and includes number of Indian youth, number of contacts, and seriousness of contacts. The final analys is covers the period from $\mathrm{O}_{4}$ to $\mathrm{O}_{5}$ or the post-treatment phase. It is assumed that this phase will cover six month period.

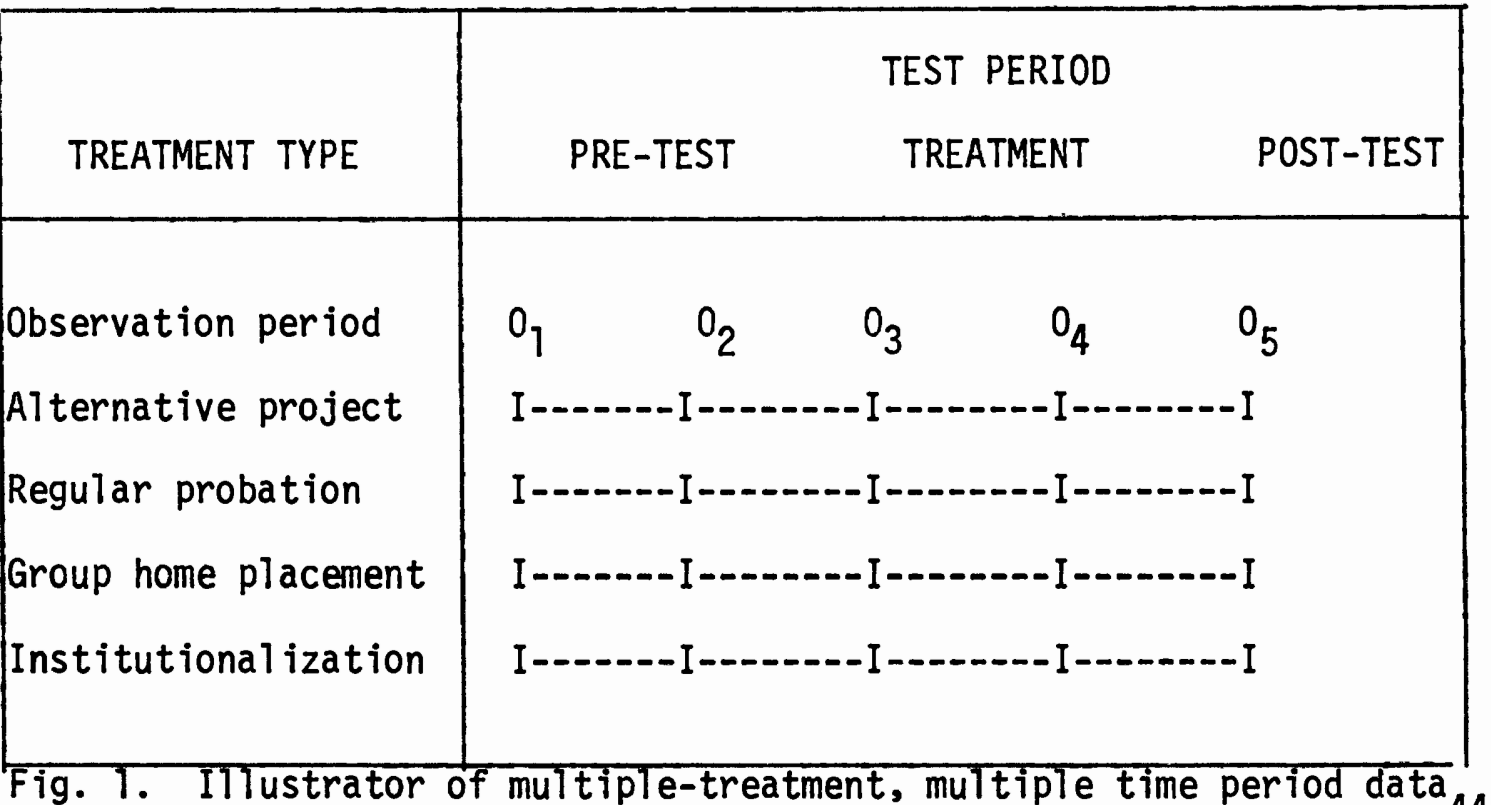
analys is for evaluation of the Alternatives for Indian youth project. 44

43 Miller, Op. Cit., pp. 48-67.

${ }^{44}$ Springer, Op. Cit. 
The model presented above rests heavily on two assumptions. First, that access will be granted to the records of youth not directly involved in the project. Second, that sufficient funds will be made available to conduct the analysis. At the time this proposal was prepared, neither of these assurances have been gained. Accordingly, a less ambitious evaluation model will also be presented; one which does not require access to records for youth other than individuals involved in the project and which would require less than two thousand dollars to implement. The two thousand dollar figure has been estimated as being available for the evaluation portion of the program.

Option B: A more modest model would concentrate solely on the project youth population. Excluded would be all data collection for the Indian youth who were assigned to other treatment methods. With these qual ifications, model would be the same as suggested above. Statistical tests would be changed since multiple comparisons would no longer be involved. In lieu of these multiple comparison tests, t-tests 45 would be used to determine where significant differences had occured between six-month pre-test court contacts. In this model youth would constitute an "own-control" group and the number of Court contacts as well as the seriousness of these contacts would be evaluated. These two comparisons represent the second and thier objectives cited for the impact evaluation of the project. The first objective, fewer youth being involved in subsequent contacts will be evaluated using Chi-square statistics. ${ }^{46}$

45 Miller, Op. Cit., pp. 8-86. ${ }^{46}$ Spiegel, Op. Cit., pp. 201-204. 
It must be noted that this represents a cone-group pre-test, post-test design as identified by Campbel1 and Stanley. 47 This is a vastly inferior design for a variety of reasons. Internal validity issues (did the program do what it claimed it would do?) are substantial and serious. A positive outcome for the project would still cause a variety of questions to be raised. Can it be stated with any reasonable degree of certainty that the effects of the program are a consequence of youth maturing and that this maturation effect over a period of time is more nearly responsible for changes in behavior than the treatment program? It cannot. Can it be stated with a reasonable degree of certainty that changes in behavior are a consequence of some undefined combination of special selection and maturation rather than program impact? It cannot.

Beyond the concerns which deal with the internal validity of the program, there are concerns related to external validity. Can one generalize from the outcome of this project to other similar populations? One cannot.

The point in the preceeding paragraphs is not that a less impressive model is useless but rather, a less sophisticated research model yields less impressive and satisfactory results. In short, the price to be paid for a lesser model needs to be acknowledged in advance-prior to implementation of any evaluation effort. It may be that this price will need to be paid, but users should be made aware of the weaknesses of the model.

Regardless which option for evaluation is selected, measurement

47Donald T. Campbell and Jul ian C. Stanley, Experimental and Quasi-Experimental Designs for Research, Rand McNaTly \& Co., Chicago, ITlinois, 1963, p. 13 . 
of a selected set of organismic variables would be highty useful. The objectives for the project have been limited to those relating to subsequent delinquent behavior up to this point. However, additional questions should be asked, given the innovative treatment proposed for the project's program. Are youth changed in ways other than del inquent behavior? Are they more confident, less involved with problems that are typical for youth at their age whether del inquent or not? To answer these questions it will be necessary for project staff and other Indian professionals to identify and administer valid measurement instruments which are relevant to Indian youth (e.g., Tennessee SelfConcept Scale). 48

48 William H. Fitts, Ph.D., Tennessee Self-Concept Scale, Counselor Recordings and Tests, Nashville, Tennessee, 1964. 
VII. Sample Forms

A. HOUSE PARENT SUPERVISING COUNSELOR RESPONSIBILITIES

1. Develop treatment team concept (Foster and maintain an atmosphere conducive to change for students and staff.)

a. Hire and supervise other team members.

b. Train students.

c. Schedule full staff cottage coverage.

2. Develop and maintain a constructive therapeutic cottage culture.

a. Conduct daily group discussions.

b. Develop individual treatment plan for every youth.

3. Work with families (individual and group counseling).

4. Public relations work with Probation Departments and families.

5. Complete cottage responsibility, around the clock, for all students and activities (on and off grounds).

6. Assume responsibility for general grounds behavior of all students (movies, recreation, meals, chapel, check-ups, etc.).

7. Maintain cottage population.

8. Transportation:
a. Store trips.
b. Passes-Vacations.
c. Medicals and legals.

9. Supervise cottage on all work assignments.

10. Keep proper accounting records of cottage funds (cottage fund, recreation money, etc.).

11. Participate in weekly business and in-service staff training meetings.

12. Maintain contact with all staff (school, work experience, etc.).

13. Assist in cottage inter-mural sports events.

14. Maintain appropriate Washington State Driver's license and insurance. 
15. Work with staff psychiatrist, psychologist, and other professional staff.

16. Keep monthly record of parent/student contacts, family. (Treatment activity form.)

17. Assist boys in draft registration and military examinations.

18. Supervise filling out and recording purchase orders.

19. Supervise marking and care of clothing.

20. General cottage appearance and upkeep (inside and outside).

21. Assume duty counselor responsibilities on designated days.

22. Illegal activities on or off duty will not be tolerated.

23. No physical abuse by staff will be acceptable.

SALARY IS BASED ON EDUCATION AND EXPERIENCE.

SALARY RANGER PER MONTH: $\$ 850-1236$

Job Performance and Salary to be re-evaluated after six months and annually thereafter. 
B. TREATMENT PLAN

Name: Date of Placement: Last First Middle

Placement Agency: Probation Officer

1. ASSIGNMENT AND EVALUATION:

A. Minor

1. General Attitude of Child Toward Placement:

2. Social Adjustment:

3. Any Special Problems Experienced:

B. Nature of Home and Family Relationship:

2. SPECIFIC GOALS:

A. Short-term:

B. Long-term: 
3. TREATMENT MODALITIES (Problem Areas to deal with):

A. Family Counseling:

B. Group Counseling:

C. Individual Counseling:

D. Social-Academic Plan:

E. Community Passes:

F. Visiting:

G. Other:

4. Treatment Plan prepared by:

Name Position

Approved By:

Supervising Counselor

5. Date: 


\section{ENROLLMENT FORM}

Name

\#

A.K.A.

DATE OF ENROLLMENT

MEDICAL

SOCIAL SECURITY NO.

School Last Attended

City

LEGAL GUARDIAN:__Father ___ Mother __other (If other, state relationship):

CURRENT ADDRESS OF :

Father:

Phone:

Area Code Number

Phone:

Area Code Number

Mother:

Phone:

Area Code Number

Phone:

Area Code Number

BIRTHDATE:

BUILD:

TRIBE :

AGE:

EYES:

RELIGION:

HEIGHT:

COMPLEXION:

GLASSES :

WEIGHT:

HAIR:

MARKS \& SCARS:

Was youth detained at Juvenile Hall prior to placement at With whom was (s)he residing prior to placement? 
D. REASONS FOR RELEASE FORM

\begin{tabular}{l|l|l}
\hline \multicolumn{2}{c|}{ DROPS } & HONORABLE DISCHARGE \\
\hline $\begin{array}{c}\text { AWOL } \\
\text { Precipitated }\end{array}$ & $\begin{array}{c}\text { No AWOL } \\
\text { Precipitating } \\
\text { Incident }\end{array}$ & $\begin{array}{l}\text { Term Term \& Grad Cond } \\
\text { Only Grad Oniy Term }\end{array}$ \\
\hline G. P.O. FAM. AGREE & G. P.O. FAM. AGMT. & \\
\hline
\end{tabular}

DROP UNDER 3 MONTHS: ( ) YeS ( ) No

$\begin{array}{rlll}\text { RELEASED: } & (\text { ) Home } & (\text { ) Foster Home } & (\text { Institution } \\ & () \text { Military } & (\text { ) Other } & (1) \text { No Information }\end{array}$

REASON FOR DROP:

COUNSELOR'S PREDICTION:

Counselor: 
Association on American Indian Affairs. Indian Family Defense No. 1 (Winter, 1974).

Blanchard, E. Mental Health: An Indian Point of View. Fall Lecture Series, 1976; School of Social Work, U. of Washington.

Blanchard, E. Organization and Indian Women. Published paper, 1977.

Bryde, J. F.: The Indian Student: A Study of Scholastic Failure and Personality Conflict, Daokta Press, 1970.

Byler, W., Deloria, S., and Gurtwitt, A. Another Chapter in the Destruction of American Indian Families. Yale Reports No. 654 (October 21, 1973).

Byler, W. Statement before the Subcommittee on Indian Affairs of the U.S. Senate on April 8, 1974. Indian Child Welfare Program. Hearings before the Subcommittee on Indian Affairs, U.S. Senate. Washington, D. C.: U. S. Government Printing Office: 1975

Campbe11, Donald T. and Stanley, Julian C. Experimental and Quasiexperimental Designs for Research. (Rand McNalTy and Co., Chicago, 1963.)

Erikson, E., Childhood and Society. W. W. Norten and Co., Inc. New York, New York. 1950.

Filts, William H., Ph.D., Tennessee Self-Concept Scale, Counselor Recordings and Lists, Nashville, Tennessee, 1964.

Garrett, Annette. Modern Casework: The Contributions of Ego Psychology. Ego Psychology and Dynamic Casework. Family Service Association of America. New York. 1972.

Goldstein, G. S. The Model Dormitory. Psychiatric Annals 4: No. 11 (November, 1974).

Hall, C. S. and Lindzey G., Freud's Psychoanalytic Theory. Theories of Personality. John Wiley \& Sons, Inc. New York. 1957.

"Juvenile Delinquency Among the Indian," Interium Report of the Subcommittee to Investigate Juvenile De Tinquency to the Committee in the Judiciary, 84 th Congress, First Session, 1955. U. S. Government Printing Office: 1955.

Law and Justice Planning Office, Office of Comunity Development, Office of the Governor, State of Washington 1975. State of Washington 1976 Comprehensive Plan for Crime Control. 
Bibliography-con't

Law and Justice Planning Office, Office of Community Development, Office of the Governor, State of Washington, 1976. State of Washington 1977 Comprehensive Plan for Crime Control and Delinquency Prevention.

Law and Justice Planning Office, Office of Community Development, Office of the Governor, State of Washington, September, 1976. State of Washington, $1977 \mathrm{Plan}$ for Juvenile Justice and The Administration of Justice.

Lewin, Kurt. Resolving Social Conflicts; Selected Papers on group Dynamics, Gertrude W. Levin (Edi), New York: Harper \& Row, 1948.

Lippett, Ronald, Watson, J. and Westley, B., The Dynamics of Planned Change: A Cooperative Study of Principles and Techique: New York, 1958.

Meissner, Doris M., Acting Chairman, Office of Policy and Planning, Published paper, Report of the Task Force on Indian Matters. Washington, D. C., October, 1975.

Miller, Jr. Rupert G., Simultaneous Statistical Inference. (McGrawHill Book Company New York, 1966.)

Minde 11, C. and Gurwitt, A., The Placement of American Indian ChildrenThe Need for Change. The Destruction of American Indian Families. Association on American Indian Affairs; New York. 1977.

Murtiel, Miguel, "The Social Science Myth and the Mexican American Family," El Grito, Vol. 3, No. 4, Summer, 1970.

National Advisory Commission on Criminal Justice Standards and Goals, Corrections. January, 1973. Washington, D. C.

Rodham, H. Children Under the Law. Harvard Educational Review 43: No. 4 (November, 1973).

Spiege 1, Murray R. Theory and Problem of Statistics. (McGraw-Hill Book Company, New York, 1961.)

Springer, Harry C., Social Agency Refusal Profit: Program Efforts and Accomplishments, Unpublished Manuscript, 1972.

Townsley, H. C., One View of The Etiology of Depression In The American Indian. PubTished Md. paper, 1976.

U. S. Senate, Special Subcomittee on Indian Education. Hearings. Washington D. C. ; U. S. Government Printing Office: 1969.

von Bertauffy, Ludwig, General Systems Theory, Brazeela, Inc., New York, 1968. 
Bibliography-con't

Weiss, Carol H., Evaluation Research (Prentice-Hall Inc., englewood Cliffs, New Jersey, 1972.) 